\title{
Review of the New World genus Nanium Townes, 1967 (Hymenoptera: Ichneumonidae: Ctenopelmatinae), with two new species from the Neotropical region
}

\author{
Alexey RESHCHIKOV ${ }^{1, *}$, Ilari E. SÄÄKSJÄRVI² \& Marc POLLET ${ }^{3}$ \\ ${ }^{1}$ State Key Laboratory of Biocontrol, Ecology and Evolution, School of Life Sciences, \\ Sun Yat-sen University, Guangzhou 510275, Guangdong, China. \\ ${ }^{2}$ Biodiversity Unit, FI-20014 University of Turku, Finland. \\ ${ }^{3}$ Research Institute for Nature and Forest (INBO), Herman Teirlinckgebouw, \\ Havenlaan 88 bus 73, B-1000 Brussels, Belgium. \\ *Corresponding author: Alexey.Reshchikov@gmail.com \\ 2Email: ilari.saaksjarvi@utu.fi \\ 32Email: mpollet.doli@gmail.com \\ ${ }^{1}$ urn:1sid:zoobank.org:author:07D32488-FBC9-4863-91EB-80800C114A9C \\ ${ }^{2}$ urn:lsid:zoobank.org:author:2B80E7A4-FEA6-4493-80C1-5B28FB0CDB8F \\ ${ }^{3}$ urn:1sid:zoobank.org:author:60A8DFC3-1A7B-4B08-999D-BBAC5ECF04C5
}

\begin{abstract}
Nanium Townes, 1967 is a small New World parasitoid wasp genus in the subfamily Ctenopelmatinae Förster, 1869 (Hymenoptera: Ichneumonidae). Previously, it comprised five species: one from North America and four from Costa Rica. The current study reviews the Neotropical species of the genus, and includes descriptions of two new species, $N$. medianum Reshchikov \& Sääksjärvi sp. nov. from Ecuador and N. atitlanensis Reshchikov \& Sääksjärvi sp. nov. from Guatemala. A key to the species is provided.
\end{abstract}

Keywords. Amazonia, Andes, Central America, Perilissini, koinobiont endoparasitoid, parasitoid wasps.

Reshchikov A., Sääksjärvi I.E. \& Pollet M. 2018. Review of the New World genus Nanium Townes, 1967 (Hymenoptera: Ichneumonidae: Ctenopelmatinae), with two new species from the Neotropical region. European Journal of Taxonomy 459: 1-18. https://doi.org/10.5852/ejt.2018.459

\section{Introduction}

The genus Nanium Townes, 1967 is a small genus in the tribe Perilissini Thomson, 1883 (Hymenoptera: Ichneumonidae: Ctenopelmatinae) and is only known from the New World (Townes 1967). Five species have been described prior to the present study, N. capitatum Cresson, 1864 from the Nearctic region (Cresson 1864), and four species from Costa Rica (Gauld 1997). The latter author also reported that more undescribed species occurred in the Neotropical region. 
Morphologically, members of Nanium are similar to small-bodied species of Lathrolestes Förster, 1869. The genus Nanium can be distinguished from other ctenopelmatines by the following set of characters: epicnemial carina extending to the anterior margin of the mesopleuron, pterostigma short and very deep, propodeal carinae absent, and propodeum and $\mathrm{T}_{1}$ granulate.

Hosts of species of Nanium are unknown, but their similarity to Lathrolestes suggests they too might attack small-bodied sawflies inhabiting wet mountains. Gauld (1997) suggested Pergidae Rohwer, 1911 (Hymenoptera: Symphyta: Tenthredinoidea) as potential hosts. Nanium seems to be restricted, at least in the Neotropics, to higher elevations.

Samples from surveys in Central and South America contained two new species of Nanium. In the present paper, both are described, and we also provide diagnoses and images of all species of Nanium, as well as a key to all species.

\section{Material and methods}

The holotype female of $N$. atitlanensis Reshchikov \& Sääksjärvi sp. nov. was found in Malaise trap samples collected during the Leaf Litter Arthropods of Mesoamerica project (LLAMA, coordinated by Dr John Longino) along the Atlantic slopes of the Central American Cordilleras in Guatemala, Honduras and Nicaragua, during the transition from the dry to wet season between May and June of 2009, 2010 and 2011. The holotype was found in a sample collected in a mature cloud forest at $1590 \mathrm{~m}$ a.s.l. For more information on the ichneumonids in these samples and their altitudinal distribution and diversity, see Veijalainen et al. (2014).

Two female specimens of $N$. medianum Reshchikov \& Sääksjärvi sp. nov. were obtained during a short term entomological survey in the Podocarpus Parque Nacional and the adjacent Reserva Biológica San Francisco in the southern Ecuadorian Andes in 2009 (provinces Loja and Zamora Chinchipe) (Pollet 2009, 2010). The third author participated in this survey, focusing primarily on Dolichopodidae (Diptera). From February $13^{\text {th }}$ to March $5^{\text {th }} 2009$ three separate areas were intensively sampled: Bombuscaro (premontane forest at around $1000 \mathrm{~m}$ a.s.1.), San Francisco (lower montane forest at around $2000 \mathrm{~m}$ a.s.1.) and Cajanuma (upper montane forest at around $3000 \mathrm{~m}$ a.s.1.). In each area a primary and two supplementary sampling sites (four at San Francisco) were selected. The basic set-up in a primary site consisted of a single Malaise trap and four units of ten pan traps of four different colors (yellow, white, blue and red). At each supplementary site, ten yellow pan traps were in operation, in order to gather information on the representativeness of the primary site. All traps were installed at soil surface level along extant forest trails or within the forest itself. Pan traps were emptied after five to seven days, the Malaise traps only once at the end of the sampling period. Additional samples were also gathered with sweep nets, and special attention was paid to microhabitats such as rocks in rivers, springs, waterfalls and tree trunks. For each sampling site the yields of five pan traps of the same color were pooled during each of the three servicing actions. The continuous sampling campaign ultimately yielded three Malaise trap samples, 118 pooled pan trap samples and 200 sweep net samples. Nanium was only collected at the Cajanuma $3000 \mathrm{~m}$ a.s.l. area, in two different sampling sites and with two different methods (Malaise trap, yellow pan traps).

Morphological terminology follows Gauld (1997). Images of specimens were taken with a Canon EOS 5D digital camera and stacked using Zerene ${ }^{\mathbb{B}}$ software. The height of the lower face is defined as the distance from the clypeal margin to the antennal insertion.

\section{Morphological abbreviation}

$\mathrm{T}=\quad$ metasomal tergites, with $\mathrm{T}_{1}$ being the anterior-most tergite 


\title{
Institutional and other abbreviations
}

$\begin{array}{ll}\text { ANSP } & \text { Academy of Natural Sciences of Philadelphia, Philadelphia, Pennsylvania, USA } \\ \text { BMNH } & \text { Natural History Museum, London, United Kingdom } \\ \text { MNCR } & =\text { National Museum of Costa Rica, San José, Costa Rica } \\ \text { MT } & \text { Malaise trap } \\ \text { MZLU } & =\text { Museum of Zoology, Lund University, Lund, Sweden } \\ \text { RBINS } & =\text { Royal Belgian Institute of Natural Sciences, Brussels, Belgium } \\ \text { UMSP } & =\text { University of Minnesota Insect Collection, St. Paul, Minnesota, USA } \\ \text { YPT } & =\text { Yellow pan traps } \\ \text { ZMUT } & =\text { Zoological Museum University of Turku, Turku, Finland }\end{array}$

\section{Results}

\author{
Class Hexapoda Blainville, 1816 \\ Order Hymenoptera Linnaeus, 1758 \\ Superfamily Ichneumonoidea Latreille, 1802 \\ Family Ichneumonidae Latreille, 1802 \\ Subfamily Ctenopelmatinae Förster, 1869 \\ Tribe Perilissini Thomson, 1883
}

Genus Nanium Townes, 1967

Nanium Townes, 1967: 174-175.

\section{Type species}

Tryphon capitatus Cresson, 1864, by original designation.

Diagnosis (Updated from Townes 1970)

Generally small-bodied species (3-6 mm), similar to the smaller species of Lathrolestes. Can be distinguished from the latter by the absence of propodeal carinae, except occasional traces of median longitudinal carinae posteriorly, and by the granulate sculpture on the propodeum and $\mathrm{T}_{1}$. In contrast with other genera of Perilissini, the epicnemial carina in Nanium extends to the anterior margin of the mesopleuron, the pterostigma is short and the marginal cell is also short and deep. The genus can further be characterized as follows: clypeus with ventral margin thick and bluntly rounded, thinner laterally, without small lateral tooth or projection. Ventral margin of clypeus convex. Epistomal sulcus usually distinctly present. Clypeus in profile not projecting or only very weakly angled outwardly from face. Malar space distinct, from very short $(0.2 \times$ basal width of mandible) to moderately long $(0.3-0.5 \times$ basal width of mandible). Diameter of lateral ocellus much shorter than the distance between ocellus and eye. Maxillary palp moderately long, about equal to head height. Female antenna ranging from as long as to slightly, but distinctly, longer than body. Occipital carina dorsally complete, its lower part joining hypostomal carina distinctly above base of mandible. Dorsal end of epicnemial carina extending to anterior margin of mesopleuron. Notaulus varying from nearly absent to distinctly impressed on anterior declivity, extending posteriorly to level of tegula as a weak groove. Groove present between propodeum and metanotum indistinct in lateral view. Propodeal carinae usually completely absent (occasionally traces of median longitudinal carinae). Apex of mid tibia somewhat evenly rounded, with at most a small, weak tooth (similar to several species of genus Perilissus Förster, 1855). Apex of hind tibia with poorly developed comb, with setae widely spaced, not dense. Posterior hind tibial spur at least $7 \times$ longer than maximum width at base. Claws varying from completely pectinate to pectinate only in basal half. Fore wing nearly always with vestigial areolet. Pterostigma short, broad, with $R s+2 r$ arising 
near middle of pterostigma. Hind wing with first abscissa of $M+C u 1$ strongly bowed; distal abscissa of $C u l$ not always discernible but when visible, joining cu-a closer to $1 A$ than to $M$; distal abscissae of $1 A$ and $C u$ spectral, vestigial or absent. $\mathrm{T}_{1}$ varying from moderately long and slender to shorter, distinctly broadening posteriorly and flattened dorsally. Dorsal carinae absent. Basal depression at dorsal tendon attachment absent. Dorsal-lateral carina absent or nearly so between spiracle and apex of $\mathrm{T}_{1}$. Glymmae on each side meeting on the midline posterior to dorsal tendon attachment, large, deep, and separated at midline by translucent partition. $\mathrm{T}_{2}$ with thyridium absent. Ovipositor straight, short, with very broad, deep, subapical depression. Ovipositor sheath from narrowly rectangular to weakly expanding distally. Male parameres broad, rectangular, never strongly narrowed posteriorly. Aedeagus rounded and weakly clubbed distally.

\section{Identification key to the species of Nanium}

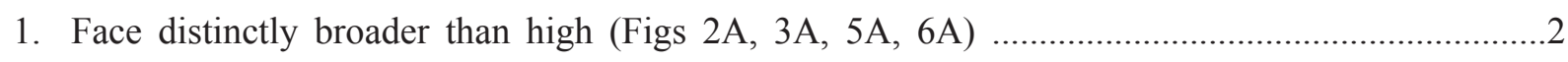

- Face at most about as broad as high (Fig. 1A) ......................................................................... 5

2. Mesosoma with yellow stripes anteriorly on mesoscutum (Fig. 5C). Metasoma with all tergites extensively pale medially (Fig. 5B) N. medianum Reshchikov \& Sääksjärvi sp. nov.

- Mesosoma black dorsally and yellowish ventrally, or entirely black (Figs 2B, 3C, 6C, 7C). Metasoma entirely black, with only $\mathrm{T}_{3}$ extensively pale, or with tergites black with hind margins narrowly yellow (Figs 2B, 3B, 6B, 7B)

3. Metasoma with $\mathrm{T}_{3}$ extensively pale (Figs $2 \mathrm{~B}, 3 \mathrm{~B}$ ), and $\mathrm{T}_{2-4}$ uniformly dark (Fig. 3B)

N. capitatum Townes, 1967

- Metasoma with $\mathrm{T}_{3}$ concolorous with $\mathrm{T}_{2-4}$ (Figs 6B, 7B) ......

4. Mesoscutum strongly polished and rather smooth. $\mathrm{T}_{1}$ about $1.5 \times$ as long as broad posteriorly (Fig. 6B)

N. nogueri Gauld, 1997

- Mesoscutum granulate. $\mathrm{T}_{1}$ about $2.3 \times$ as long as broad posteriorly (Fig. 7B)

N. oriasi Gauld, 1997

5. Pleural carina distinct. $\mathrm{T}_{1}$ less than $2.4 \times$ as long as broad posteriorly (Fig. 1A); hind coxa, at least partly, yellowish (Fig. 1C)

- Pleural carina absent. Metasoma with $\mathrm{T}_{1}$ at least $2.8 \times$ as long as broad posteriorly; hind coxa nearly entirely black

N. mairenai Gauld, 1997

6. Antenna with 26 flagellomeres. Hind tibia $9 \times$ as long as broad apically. Ovipositor sheath diamondshaped. Propleuron yellowish. $T_{3}$ yellowish with dark anterior part. Hind coxa entirely pale yellow. Hypopygium pale yellow (Fig. 4)

N. huberthi Gauld, 1997

- Antenna with 28 flagellomeres. Hind tibia $7 \times$ as long as broad apically. Ovipositor sheath gradually expanding towards apex. Propleuron dark brown (Fig. 1C). $\mathrm{T}_{3}$ entirely yellowish (Fig. 1B). Hind coxa dark brown with only its basodorsal part pale yellow (Fig. 1C). Hypopygium dark brown (Fig. 1C) ..N. atitlanensis Reshchikov \& Sääksjärvi sp. nov. 

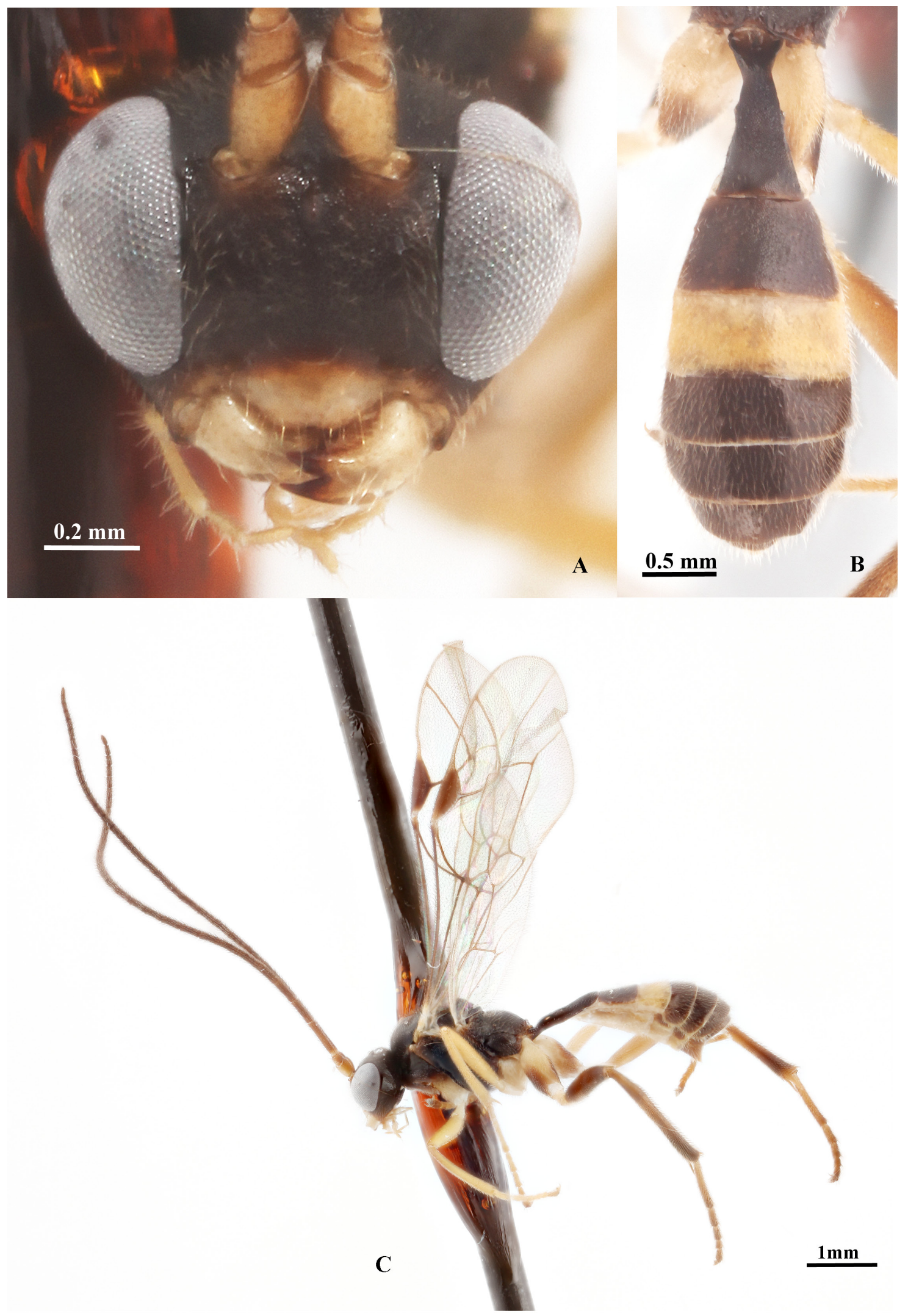

Fig. 1. Nanium atitlanensis Reshchikov \& Sääksjärvi sp. nov., holotype, + (LLAMA\#Ma-B-09-2-01 (ZMUT)). A. Face (frontal view). B. Metasoma (dorsal view). C. Habitus. 


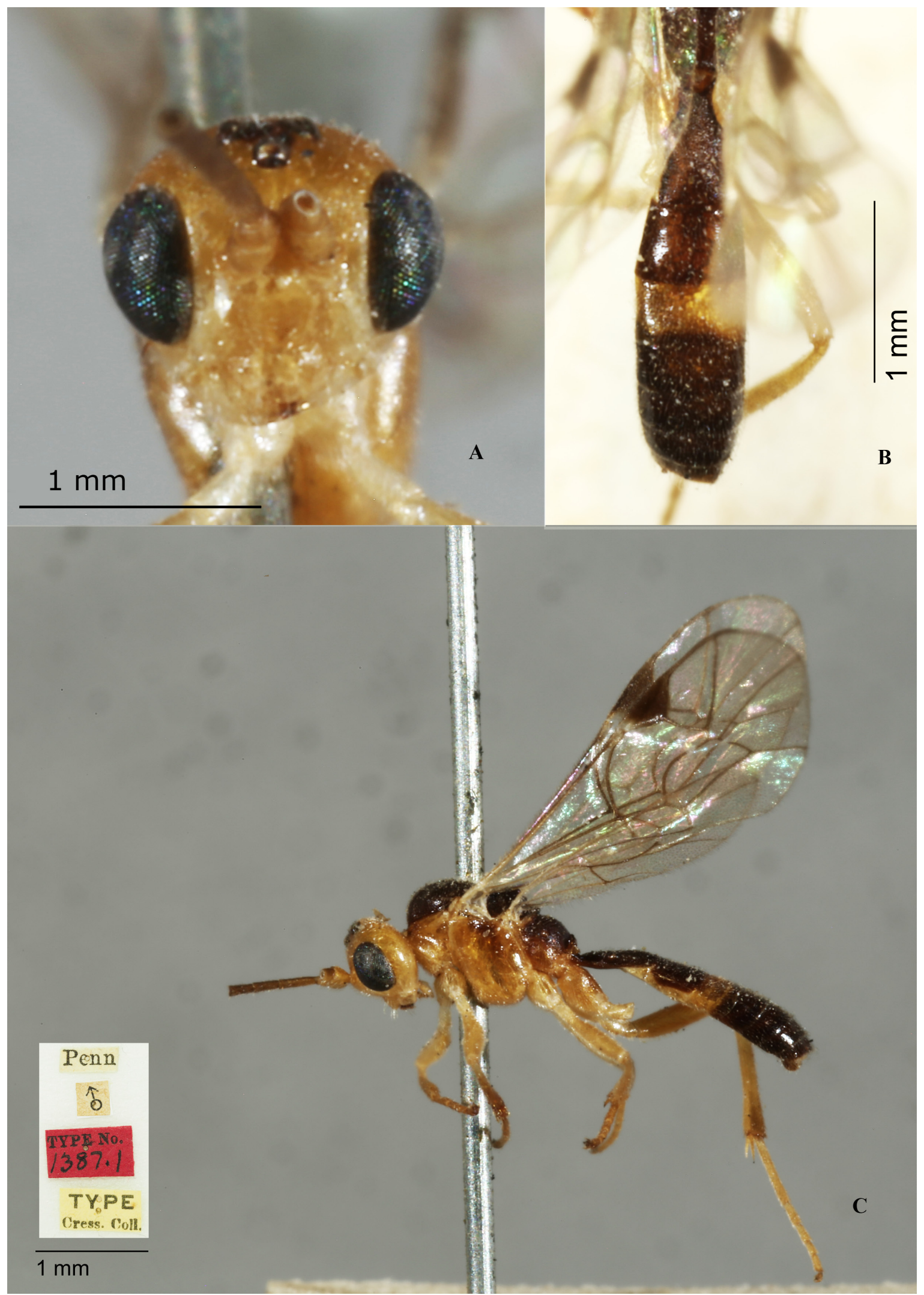

Fig. 2. Nanium capitatum Townes, 1967, lectotype, đ̊ (ANSP). A. Face. B. Metasoma (dorsal view). C. Habitus. 

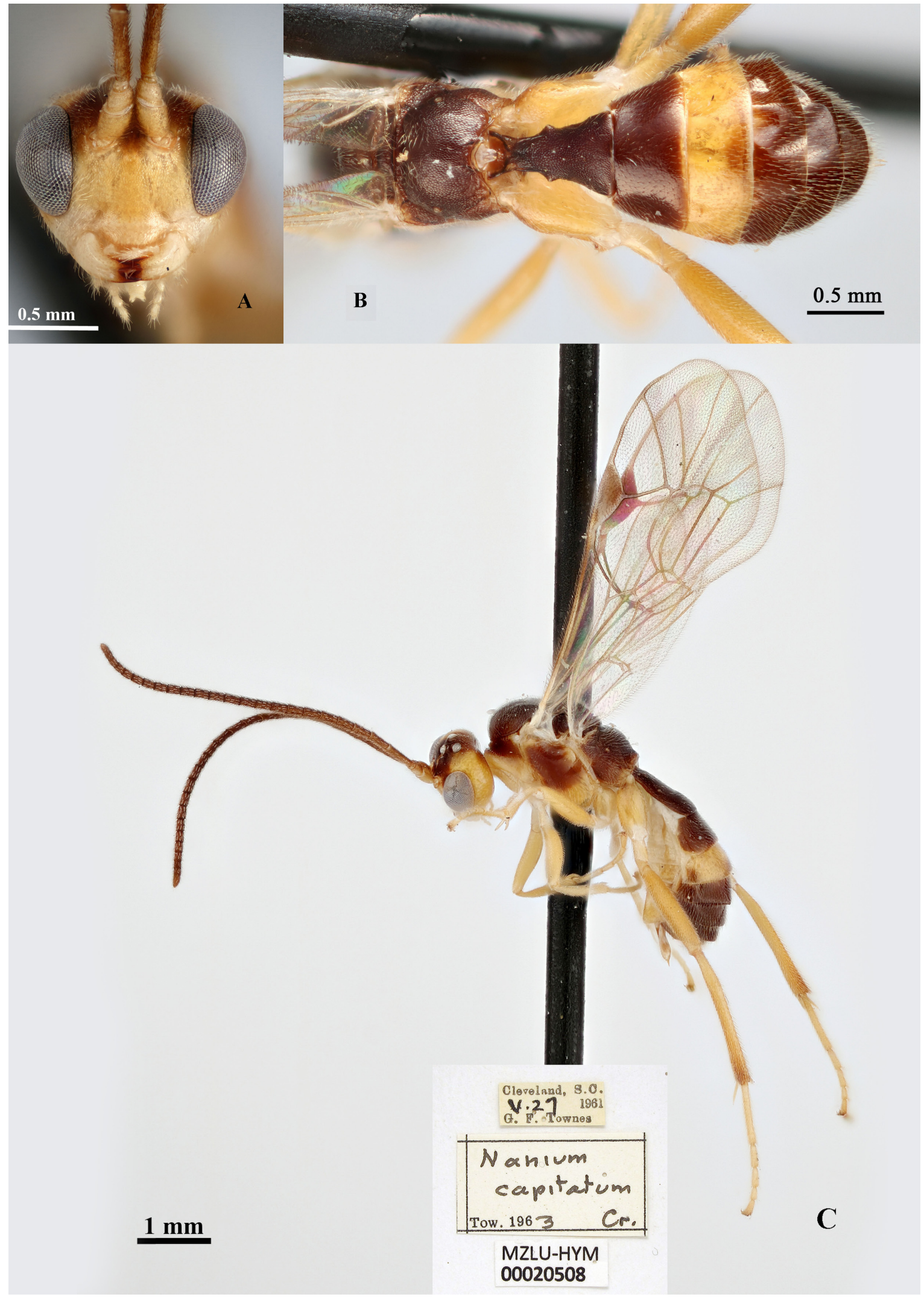

Fig. 3. Nanium capitatum Townes, 1967, q (MZLU-HYM 00020508). A. Face (frontal view). B. Metasoma (dorsal view). C. Habitus. 


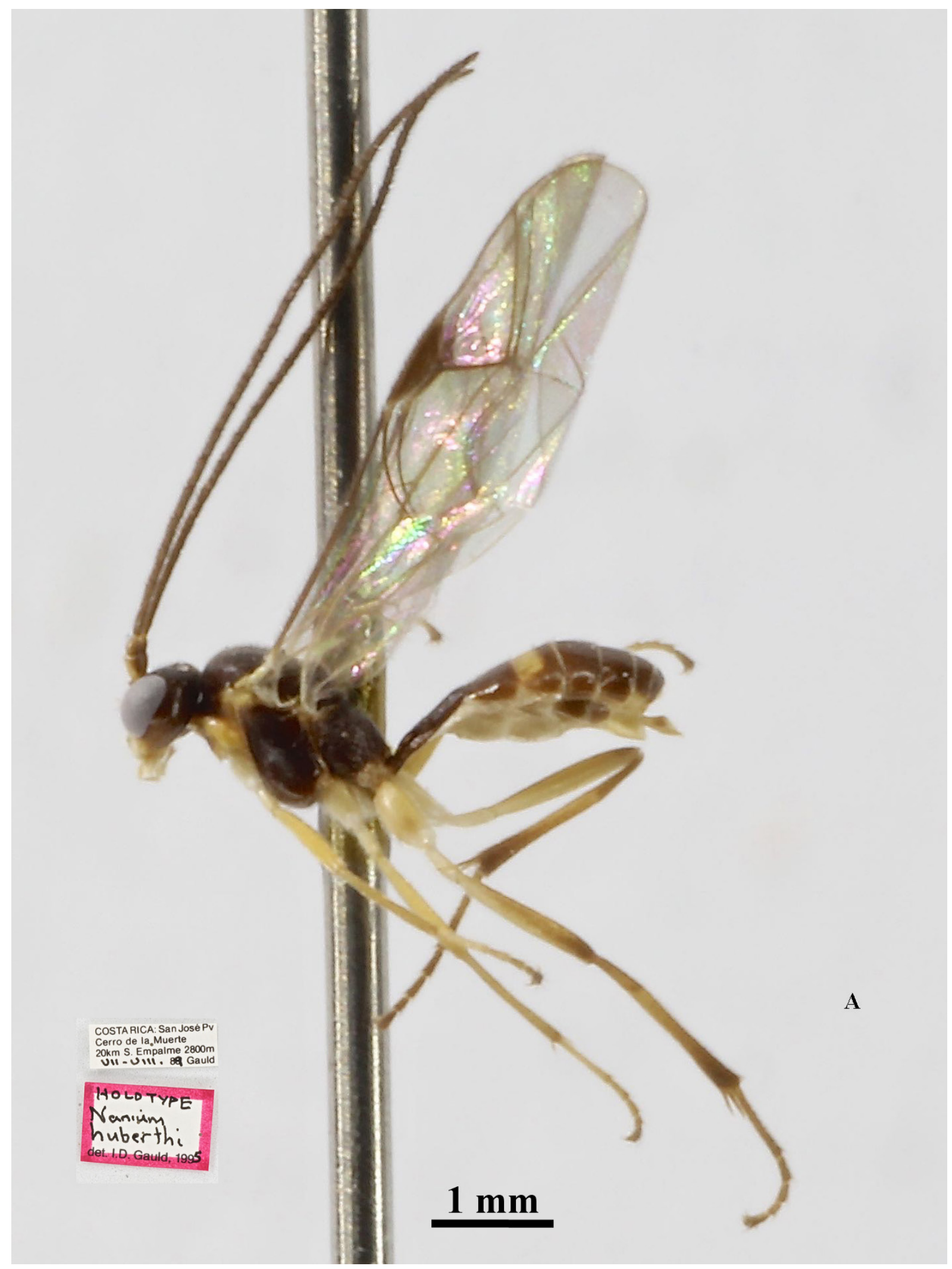

Fig. 4. Nanium huberthi Gauld, 1997, holotype, $q$, habitus (MNCR). 


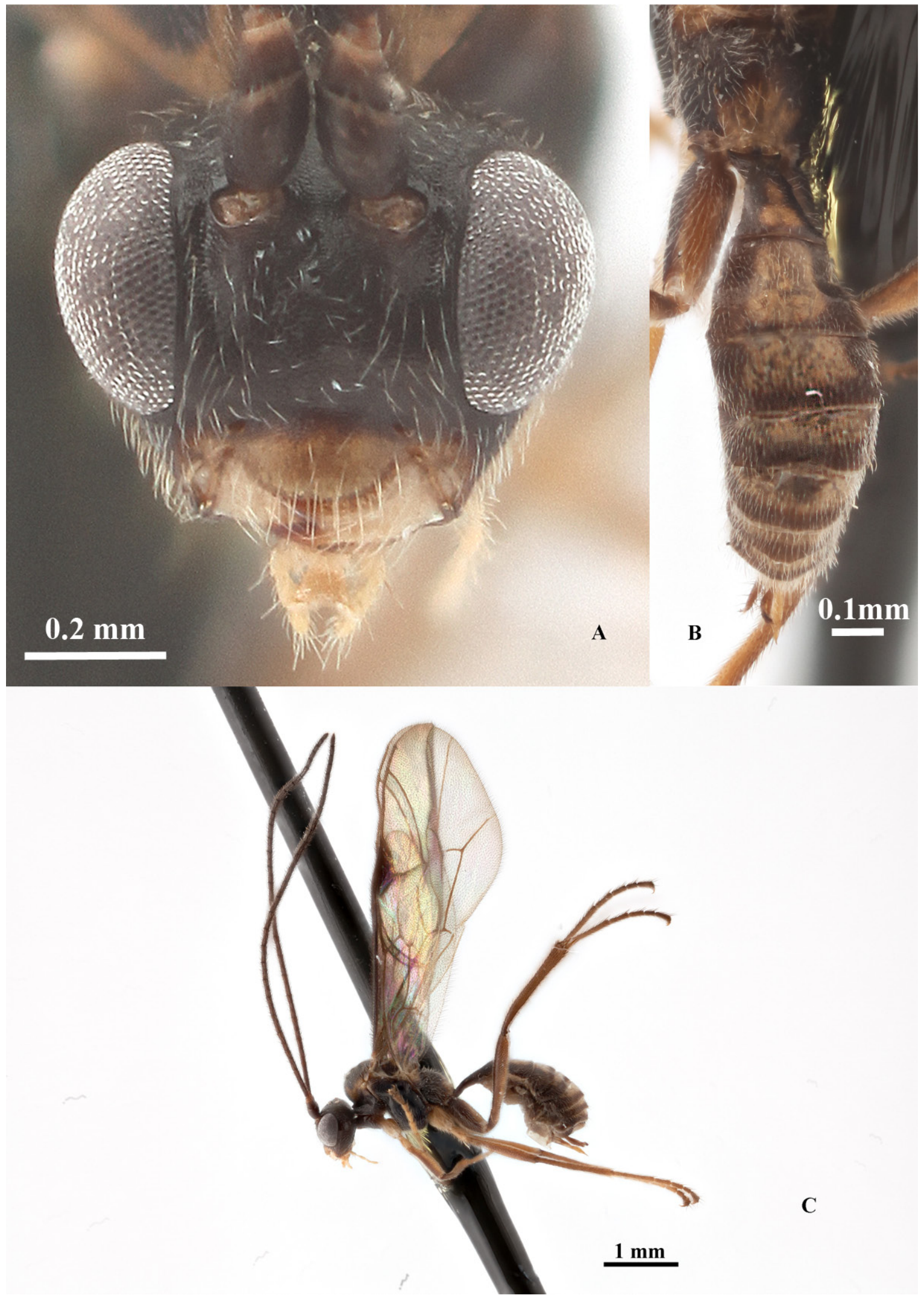

Fig. 5. Nanium medianum Reshchikov \& Sääksjärvi sp. nov., holotype, q (EC/2009-37/ MP\&ADB-013 (RBINS)). A. Face. B. Metasoma (dorsal view). C. Habitus. 


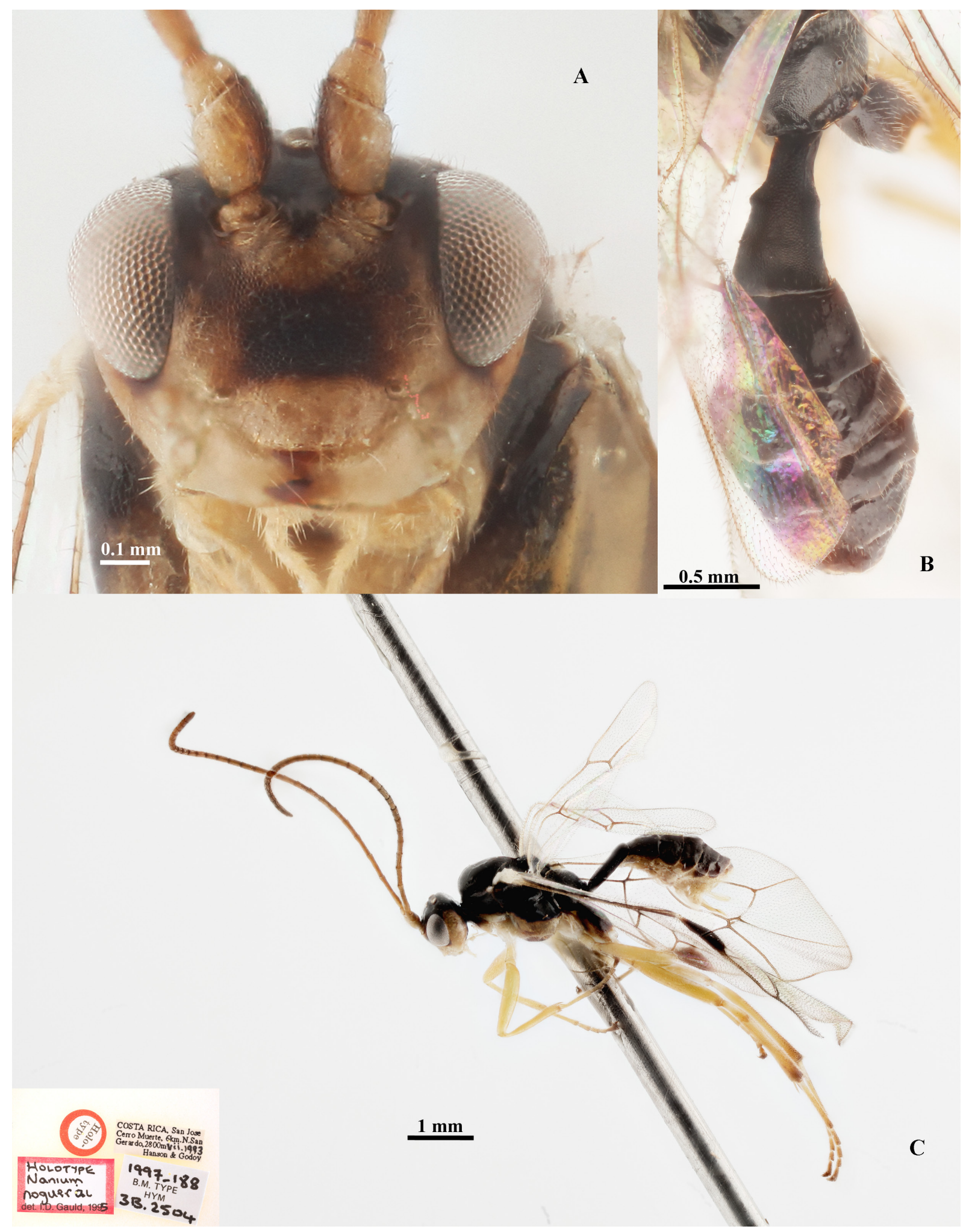

Fig. 6. Nanium nogueri Gauld, 1997, holotype, $q$ (BMNH). A. Face. B. Metasoma (dorsal view). C. Habitus. 


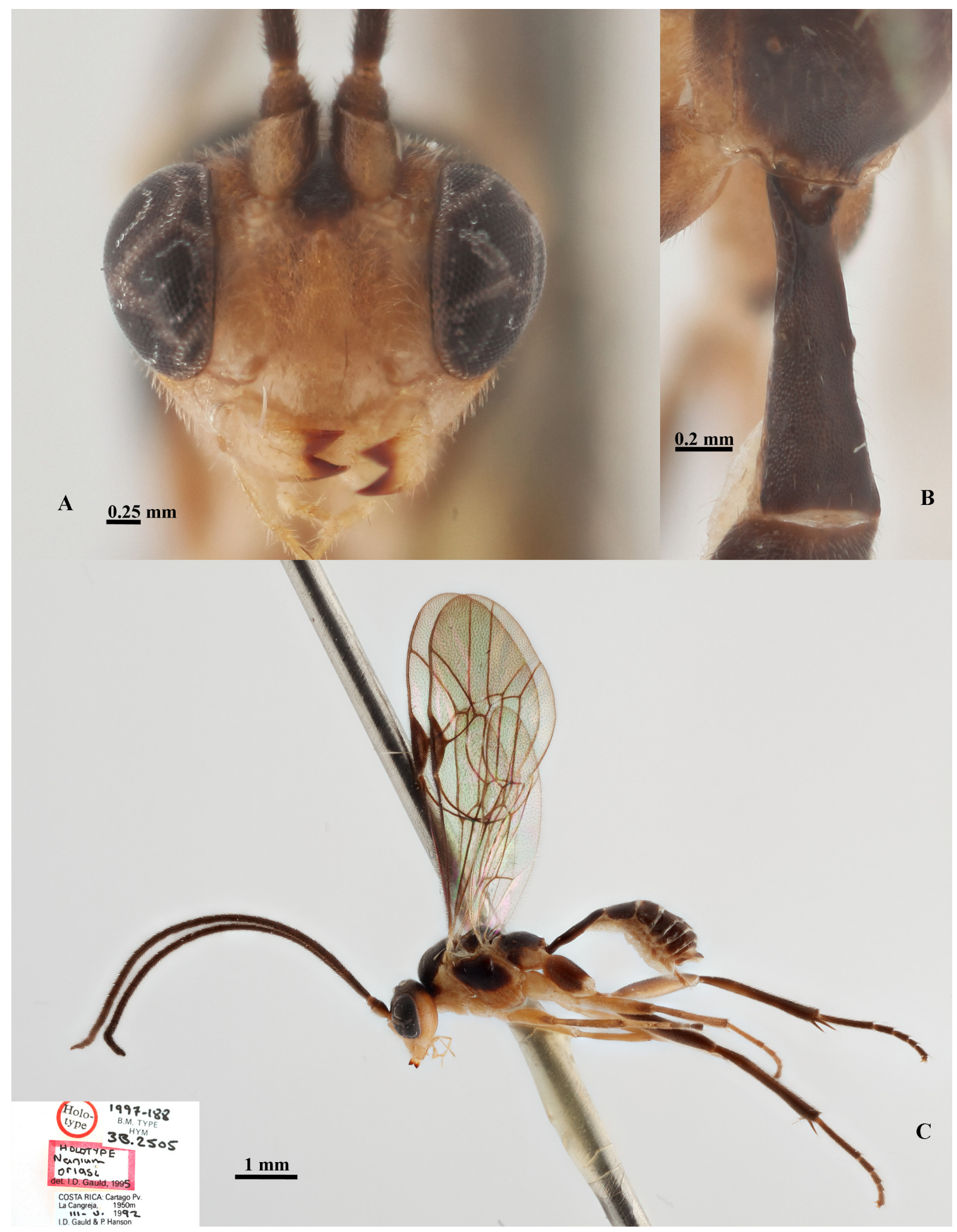

Fig. 7. Nanium oriasi Gauld, 1997, holotype, $q$ (BMNH). A. Face. B. Metasoma (dorsal view). C. Habitus. 


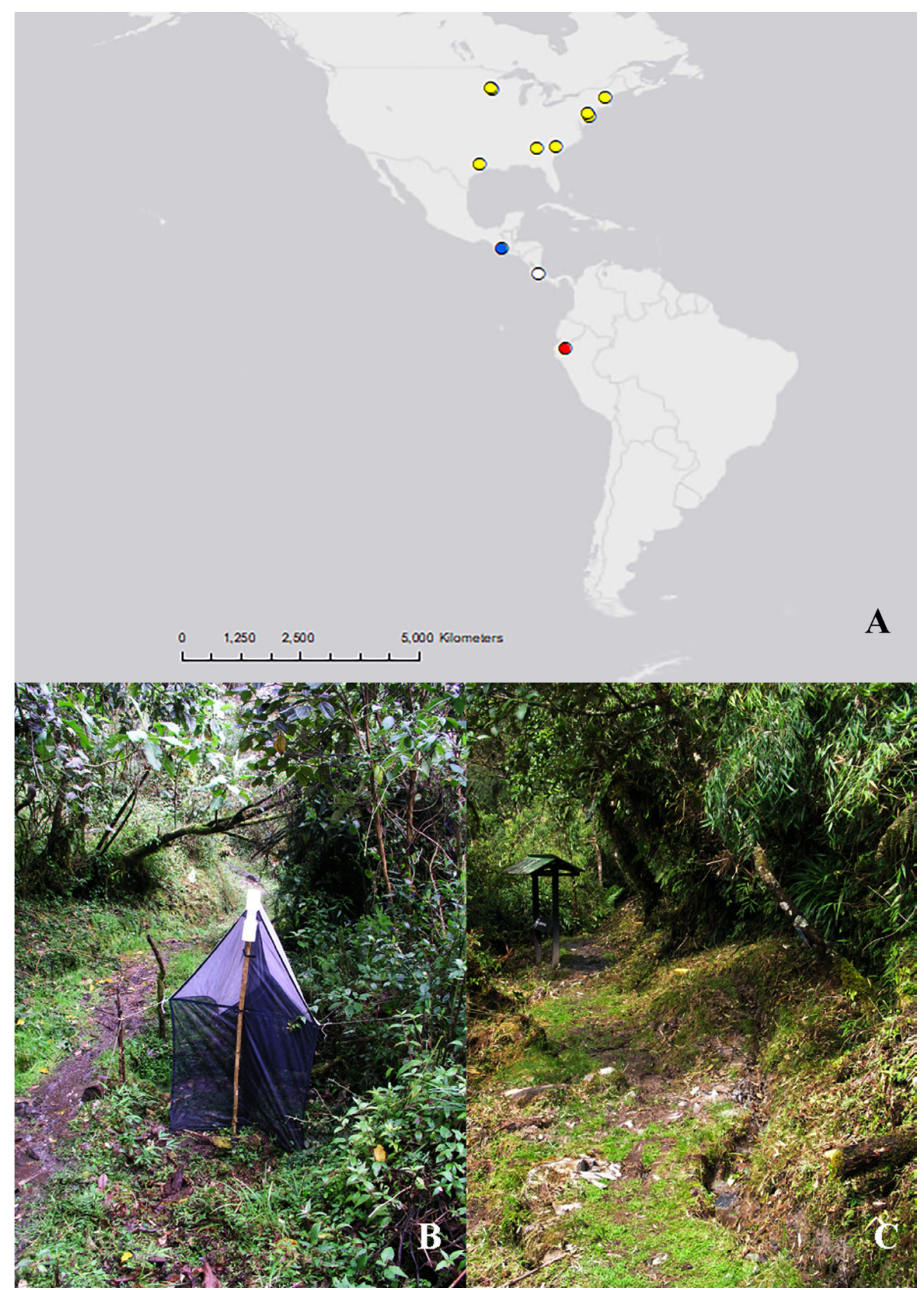

Fig. 8. Distribution and habitats of Nanium. A. Distribution of Nanium species (blue N. atitlanensis Reshchikov \& Sääksjärvi sp. nov.; yellow - N. capitatum Townes, 1967; white Costa Rican species (N. huberthi Gauld, 1997, N. mairenai Gauld, 1997, N. nogueri Gauld, 1997 , N. oriasi Gauld, 1997); red - N. medianum Reshchikov \& Sääksjärvi sp. nov.). B. Malaise trap and type locality of $N$. medianum sp. nov. on the trail Bosque Nublado, Cajanuma, Podocarpus Parque Nacional, Ecuador. C. Trail Oso de Anteojos near the type locality of N. medianum sp. nov., Podocarpus Parque Nacional, Ecuador, where the paratype specimen was captured in a yellow pan trap. 
Nanium atitlanensis Reshchikov \& Sääksjärvi sp. nov. urn:lsid:zoobank.org:act:D06E464A-EB70-4805-B612-F6C8AE030443

Figs $1,8 \mathrm{~A}$

\section{Diagnosis}

This species can be distinguished from all its congeners by the combination of the following characters: face black, at most about as broad as high (Fig. 1A); pleural carina defined; metasoma with $\mathrm{T}_{1}$ relatively short (1.9 $\times$ as long as broad posteriorly) (Fig. 1B); hind leg with coxa, at least partly, yellowish (Fig. 1C).

\section{Etymology}

The species name refers to the type locality (Volcán Atitlán).

\section{Material examined}

\section{Holotype}

GUATEMALA: 1 ㅇ, Suchitepeq, $4 \mathrm{~km} \mathrm{~S}$ of Vol. Atitlán, $1590 \mathrm{~m}$ a.s.1. $\pm 7 \mathrm{~m}, 14.54852^{\circ} \mathrm{N}, 91.19331^{\circ}$ W, wet cloud forest, MT, 14-18 Jun. 2009, sample code LLAMA\#Ma-B-09-2-01 (ZMUT).

\section{Description}

SEx. Female (Fig. 1).

BODY LENGTH. $4.5 \mathrm{~mm}$.

HEAD. Antennal flagellum with 28 segments. Scape $1.6 \times$ as long as wide. Head narrowed behind eyes, matte, rather square. Face as broad as eye height, convex, bulging, granulate (Fig. 1A). Clypeus separated from face by impression; clypeal apex strongly projecting anteriorly; apical margin of clypeus moderately obtuse, with a shallow notch; clypeal foveae small. Malar space $0.8 \times$ as wide as basal mandible width; mandibular teeth of equal length and width.

Mesosoma. Mesosoma granulate, not punctate, matte, bearing some pale setae (Fig. 1C). Notaulus absent. Epicnemial carina high, distinctly defined, almost reaching anterodorsal corner of mesopleuron. Mesopleuron matte, impunctate. Tarsal claws pectinate with small teeth at base. Fore wing without areolet; $R$ intercepting pterostigma immediately behind its middle; $2 m-c u$ with a single bulla; $c u-a$ intersticial. Hind wing with $C u 1 \& c u-a$ intercepted below middle; $C u 1$ curved, not reaching edge of hind wing. Propodeal carinae absent except defined pleural carina (Fig. 1C).

Metasoma. Metasoma cylindrical, slightly shining, granulate, impunctate, with isolated setae (Fig. 1B). First metasomal tergite $1.9 \times$ as long as broad apically, with shallow median longitudinal impression bordered by lateral longitudinal carinae. Hind margin of first metasomal sternite at level of spiracles. $\mathrm{T}_{2}$ transverse. Thyridia absent. Hypopygium triangular in profile. Ovipositor sheath slender, slightly wider apically, $0.7 \times$ as long as metasomal height.

Color. Head including face black. Clypeus and mandibles yellowish. Antenna black with scape and pedicel yellowish. Mesosoma black with pronotum yellowish ventrally; tegula yellowish. Fore and mid legs yellowish, hind leg black, with femur ventrally and coxa basally yellowish. Metasoma black, with epipleurae of $\mathrm{T}_{2}$ and $\mathrm{T}_{3}$ entirely yellowish. Pterostigma dark brown.

\section{Distribution}

Guatemala (Sololá Department). 


\section{Nanium capitatum Townes, 1967}

Figs 2-3, 8A

Tryphon capitatus Cresson, 1864: 281, lectotype examined.

\section{Diagnosis}

This species can be distinguished from all its congeners by the combination of the following characters: face obviously broader than high (Figs 2A, 3A), mesosoma black dorsally, yellowish ventrally or entirely black (Figs 2B, 3B), pleural carina complete, well-developed, metasoma with $\mathrm{T}_{3}$ extensively pale, and $\mathrm{T}_{2-4}$ uniformly dark (Figs 2C, 3C).

\section{Material examined}

Lectotype

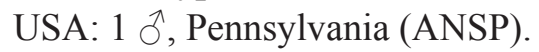

\section{Other material}

USA: 1 , South Carolina, Cleveland, 27 May 1961, Townes leg. (ZMLU); 1 , Minnesota, Ramsey

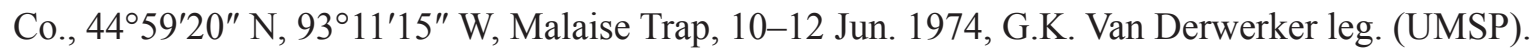

\section{Remark}

First record for Minnesota.

\section{Distribution}

USA (Georgia, New Hampshire, Minnesota, New Jersey, Pennsylvania, Texas).

\section{Nanium huberthi Gauld, 1997}

Figs 4, 8A

\section{Diagnosis}

This species can be distinguished from all its congeners by the combination of the following characters: face at most about as broad as high, entirely yellow, pleural carina defined, $T_{1}$ stout $(1.9-2.3 \times$ as long as broad posteriorly), hind coxa yellowish (Fig. 4).

\section{Material examined}

\section{Holotype}

COSTA RICA: 1 + , San José Prov., Cerro de la Muerte, 20 km S of Empalme, 2800 m a.s.1., Jul.-Aug. 1989, Gauld leg. (MNCR).

\section{Distribution}

Costa Rica (San José province).

Nanium mairenai Gauld, 1997

\section{Diagnosis}

This species can be distinguished from all its congeners by the combination of the following characters: face at most about as broad as high, entirely yellow, pleural carina lacking, $\mathrm{T}_{1}$ slender $(2.8-3.0 \times$ as long as broad posteriorly); hind coxa, trochanter, femur and distal end of tibia black, trochantellus yellowish. 


\section{Remark}

The type material was not examined.

\section{Distribution}

Costa Rica.

Nanium medianum Reshchikov \& Sääksjärvi sp. nov. urn:lsid:zoobank.org:act:4FF453E7-AD7F-4964-A5A4-CF0B4D481048

Figs $5,8 \mathrm{~A}-\mathrm{C}$

\section{Diagnosis}

This species can be distinguished from all its congeners by a combination of the following characters: face distinctly broader than high (Fig. 5A), mesosoma with yellow stripes on mesoscutum anteriorly (Fig. 5C), metasoma with all tergites extensively pale medially (Figs 5B-C).

\section{Etymology}

The name of the species refers to the characteristic coloration of the metasoma.

\section{Material examined}

\section{Holotype}

ECUADOR: 1 , Podocarpus Parque Nacional, Cajanuma, trail Bosque Nublado (sampling site PR, Fig. 8B), MT, 2750 m a.s.l., 16 Feb.-5 Mar. 2009, Marc Pollet and Anja De Braekeleer leg., sample code EC/2009-37/MP\&ADB-013 (RBINS).

\section{Paratype}

ECUADOR: 1 , Podocarpus Parque Nacional, Cajanuma, trail Oso de Anteojos (sampling site S2 (YPT06-10), Fig. 8C), 2750 m a.s.1., 27 Feb.-5 Mar. 2009, YPT, Marc Pollet and Anja De Braekeleer leg., sample code EC/2009-37/MP\&ADB-012 (RBINS).

\section{Description}

Sex. Female (Fig. 5).

Body Length. $4.7 \mathrm{~mm}$.

HEAD. Antennal flagellum with 25 segments. Scape $1.6 \times$ as long as wide. Head narrowed behind eyes, matte, roundish. Maximum length of temple $0.9 \times$ transverse eye diameter, minimum length $0.6 \times$ transverse eye diameter. Face width $1.1 \times$ height of eye (Fig. 5A). Face convex, bulging, with granulate sculpture. Clypeus separated from face by impression; clypeal apex strongly projecting anteriorly; apical margin of clypeus moderately obtuse, without shallow notch; clypeal foveae small. Malar space nearly as wide as basal mandible width. Mandible teeth of equal length and width.

Mesosoma. Mesosoma granulate, matte, impunctate, bearing scattered pale setae (Fig. 5C). Notaulus absent. Epicnemial carina high, distinctly defined, reaching pronotum. Mesopleuron matte, impunctate. Tarsal claws basally pectinate with small teeth. Fore wing without areolet; $R$ intercepting pterostigma immediately behind its middle; $2 m-c u$ with a single bulla; $c u-a$ postfurcal. Hind wing with $C u 1 \& c u-a$ intercepted below middle; $C u_{1}$ straight, not reaching edge of hind wing. Propodeal and pleural carinae absent (Fig. 5C). 
Metasoma. Metasoma cylindrical, rather shining, granulate, impunctate, with isolated setae (Fig. 5B). $\mathrm{T}_{1} 1.5 \times$ as long as wide apically, with shallow median longitudinal impression, and bordered by lateral longitudinal carinae. Hind margin of first metasomal sternite at level of spiracles. $\mathrm{T}_{2}$ transverse. Thyridia absent. Hypopygium triangular in profile. Ovipositor sheath slender, $0.7 \times$ as long as metasomal height.

Color. Body mostly dark-brown (Fig. 5). Clypeus, anterior lateral edges of mesonotum, fore and middle legs, hind coxa and femur ventrally, and medial part of metasomal tergites all yellowish-brown (Fig. 5B). Mandible yellow with brown apex. Palpus yellow (Fig. 5C).

\section{Distribution}

Ecuador (Loja province).

Nanium nogueri Gauld, 1997

Figs 6, 8A

\section{Diagnosis}

This species can be distinguished from all its congeners by the combination of the following characters: face obviously broader than high with inner margins of eyes slightly divergent ventrally (Fig. 6A); mesoscutum highly polished, rather smooth; metasoma with $\mathrm{T}_{1} 1.5 \times$ as long as broad posteriorly (Fig. 6B); metasoma uniformly black; hind femur and tibia extensively yellowish (Fig. 6C).

\section{Material examined}

\section{Holotype}

COSTA RICA: 1 + , San José Prov., Cerro de la Muerte, 6 km N of San Gerardo de Dota, 2800 m a.s.l., Jul. 1993, Hanson and Godoy leg. (BMNH).

\section{Distribution}

Costa Rica (San José Province).

Nanium oriasi Gauld, 1997

Figs 7, 8A

\section{Diagnosis}

This species can be distinguished from all its congeners by the combination of the following characters: face with inner margins of eyes parallel (Fig. 7A); mesoscutum granulate, mesopleuron not polished ventrally; mesosoma black dorsally and yellowish ventrally (Fig. 7C); metasoma with $\mathrm{T}_{1} 2.3 \times$ as long as broad posteriorly (Fig. 7B).

\section{Material examined}

\section{Holotype}

COSTA RICA: 1 + , Cartago Prov., La Cangreja, 1950 m a.s.l., Mar.-May 1992, Gauld and Hanson leg. (BMNH).

\section{Distribution}

Costa Rica (Cartago Province). 


\section{Discussion}

The main aim of the current work was to describe two new species of Nanium from Ecuador and Guatemala and to provide an illustrated identification key for the seven known members of the genus, rather than to provide a complete revision of the genus. The true species richness of Nanium may prove to be higher when more Neotropical highland localities are better sampled. By describing these two new species of Nanium we hope to draw attention to the very poorly studied parasitoid wasp faunas of the highly vulnerable tropical highlands of Central and South America.

Nanium is a New World genus. Most species seem to be restricted to tropical and subtropical parts of Central and South America and only one species, N. capitatum, has been reported from North America. Gauld (1997) described four species of Nanium from Costa Rica. All of these were found in humid localities at $1000 \mathrm{~m}$ a.s.l. or higher. The two new species described in the current work were found in samples collected at $1590 \mathrm{~m}$ and $2750 \mathrm{~m}$ a.s.l. Not a single specimen of Nanium has been detected among the tens of thousands of Neotropical ichneumonid specimens from tropical lowland forest sites (e.g., Veijalainen et al. 2013) examined thus far.

Ctenopelmatines are known to be most species-rich at northern latitudes (Timms et al. 2016) and only relatively few species have been described from the tropics. Moreover, the species might be abundant in the field, but much less so in the traps applied. For example, all species of Nanium described by Gauld (1997) from Costa Rica were represented in the samples by at most a handful specimens. This is in accordance with the current study. We have only seen two specimens of $N$. medianum sp. nov. and one specimen of $N$. atitlanensis sp. nov.

The current work also demonstrates the usefulness of examining residual samples from biodiversity inventories. Both of the new species of Nanium were, indeed, detected in residuals of samples collected during leaf litter arthropod and Diptera surveys, respectively.

\section{Acknowledgments}

The authors are thankful to John Longino (Utah Museum of Natural History, Salt Lake City, USA), Jason Weintraub (ANSP), Gavin Broad (BMNH), Wouter Dekoninck (RBINS), Rónald Zúñiga (MNCR) and Robin Thomson (UMSP) for providing material for this study, and to Tony Hunter (World Museum, Liverpool, UK) for a linguistic review of the manuscript. The first author is greatly thankful to Jon Gelhaus and all colleagues at the Entomology department of ANSP who were extremely helpful during his visit to the Academy, funded by a Jessop Fellowship. He is especially indebted to Jason Weintraub (ANSP) for his kind help in photographing a type specimen. The first author is also extremely thankful to Hege Vårdal, Kjell Arne Johanson (Swedish Museum of Natural History, Stockholm, Sweden) and Rickard Sundin (Swedish Taxonomy Initiative, Uppsala, Sweden) for their assistance during his work at the NHRS. The second author is greatly thankful to Anu Veijalainen for her kind help in sorting of the Guatemala Malaise samples in ZMUT. The participation of the third author in the Podocarpus Parque Nacional survey was financially supported by the European Distributed Institute of Taxonomy (EDIT), the Flemish Fund for Scientific Research (FWO-Vlaanderen, Belgium) and the Leopold III Fund for Nature Research and Nature Conservation (L III, Belgium). The third author is also greatly indebted to Jörg Zielinger and Dr Felix Matt, the coordinators of the San Francisco Estación Biológica, for their continuous and kind assistance during this expedition. Many thanks are also due to the Ecuadorian crew of this biological station (e.g., car drivers, cooks), and the Belgian expedition team led by Dr Maurice Leponce (RBINS) who made this survey a truly memorable event. 


\section{References}

Cresson E.T. 1864. Descriptions of North American Hymenoptera in the collection of the Entomological Society of Philadelphia. Proceedings of the Entomological Society of Philadelphia 3: 257-321.

Gauld I.D. 1997. The Ichneumonidae of Costa Rica, 2. Memoirs of the American Entomological Institute 57: $1-485$.

Pollet M. 2009. In search for dolichopodid flies in southern Ecuador: the true story. Fly Times 42: 36-51. Available from: http://www.nadsdiptera.org/News/FlyTimes/issue42.pdf [accessed 8 Aug. 2018].

Pollet M. 2010. Dolichopodid diversity assessment in Neotropical montane forest habitats (Dolichopodidae). 7th International Congress of Dipterology, Abstracts Volume: 193. Ramada-Herradura International Conference Center, San José, Costa Rica. Available from: http://www.nadsdiptera.org/ICD/ICD7/AbstractsICD7.pdf [accessed 8 Aug. 2018].

Timms L.L., Schwarzfeld M. \& Sääksjärvi I.E. 2016. Extending understanding of latitudinal patterns in parasitoid wasp diversity. Insect Conservation and Diversity 9: 74-86. https://doi.org/10.1111/icad.12144

Townes H.K. 1967. Genus Nanium Townes, n. genus. In: Krombein K.V. \& Burks B.D., Hymenoptera of America North of Mexico - Synoptic Catalog 2 (2 ${ }^{\text {nd }}$ suppl.): 174-175. U.S. Dept of Agriculture Washington. https://doi.org/10.5962/bhl.title.4124

Townes H.K. 1970. The genera of Ichneumonidae, Part 3. Memoirs of the American Entomological Institute 13: 307.

Veijalainen A., Sääksjärvi I.E., Erwin T.L., Gómez I.C. \& Longino J.T. 2013. Subfamily composition of Ichneumonidae (Hymenoptera) from western Amazonia: Insights into diversity of tropical parasitoid wasps. Insect Conservation and Diversity 6: 28-37. https://doi.org/10.1111/j.1752-4598.2012.00185.x

Veijalainen A., Sääksjärvi I.E., Tuomisto H., Broad G.R., Bordera S. \& Jussila R. 2014. Altitudinal trends in species richness and diversity of Mesoamerican parasitoid wasps (Hymenoptera: Ichneumonidae). Insect Conservation and Diversity 7: 496-507. https://doi.org/10.1111/icad.12073

Manuscript received: 9 January 2018

Manuscript accepted: 17 May 2018

Published on: 7 September 2018

Topic editor: Gavin Broad

Desk editor: Alejandro Quintanar

Printed versions of all papers are also deposited in the libraries of the institutes that are members of the EJT consortium: Muséum national d'Histoire naturelle, Paris, France; Botanic Garden Meise, Belgium; Royal Museum for Central Africa, Tervuren, Belgium; Natural History Museum, London, United Kingdom; Royal Belgian Institute of Natural Sciences, Brussels, Belgium; Natural History Museum of Denmark, Copenhagen, Denmark; Naturalis Biodiversity Center, Leiden, the Netherlands; Museo Nacional de Ciencias Naturales-CSIC, Madrid, Spain; Real Jardín Botánico de Madrid CSIC, Madrid, Spain; Zoological Research Museum Alexander Koenig, Bonn, Germany. 